\title{
Some Aspects of Computer-Aided Formative and Summative Assessments
}

\author{
Naira Avakyan, Arus Markaryan \\ Yerevan State University
}

\begin{abstract}
C omputer-aided assessment (CAA) is a term that covers forms of assessment delivered on computer, either online or on a local network, and those that are marked with the aid of computers. CAA can be viewed in a few different ways. Technically, assignments that are written on a computer and researched online are computer-aided assessments. One of the most common forms of computer-aided assessment is online quizzes or exams. They can be implemented online, and also marked by the computer by putting the answers in.

CAA covers a range of assessment procedures and is a rapidly developing area as new technologies are achieved. In essence, CAA refers to any instance in which some aspect of computer technology is set out as part of the assessment process. Some of the principle examples of CAA in language learning are: interactive exercises and tests completed on a computer, use of computers to produce coursework, on-screen marking of students' word-processed writing, use of e-mail for students to receive marks and feedback.

Computer-based exercises and tests often take the same kind of format. The essential difference between an exercise and a test is the purpose to which it is put. An exercise usually offers instant feedback to the learner and an opportunity to correct any errors that are made, whereas a test may offer little feedback to the learner apart from a raw score at the end of the test, or no feedback at all, e.g. where the results of the test might be stored for analysis by a teacher or examiner. Exercises are usually designed to offer the learner practice in specific areas and to motivate and encourage, whereas tests are usually designed to assess the learner's progress in specific areas, i.e. for self-assessment purposes, for the teacher or for an examination body. The main kinds of tests include: Placement, Diagnostic, Achievement, Proficiency, and Aptitude tests. Placement tests are designed mainly to sort students into teaching groups so that they are approximately at the same level when they join the group. Diagnostic tests enable the learner or teacher to identify specific strengths and weaknesses so that corrective action can be taken. Achievement / attainment tests are meant to show mastery of a particular syllabus rather than as a means of motivating the learner or reinforcing specific language skills. Proficiency tests measure learner's achievements in relation to a specific task which they are later required to perform. Aptitude tests aim to predict how a student might perform in specific areas of a subject.

The most common exercise types are: true or false, multiple-choice, gap-filling, word search, text reconstruction, matching, re-ordering jumbled words, re-ordering jumbled sentences, free text entry, crosswords.

Classroom assessments can include a wide range of options roughly divided into two categories: formative assessments and summative assessments.
\end{abstract}


Formative Assessments (FA) are on-going assessments, reviews, and observations in a classroom. Teachers use FA to improve instructional methods and student feedback throughout the teaching and learning process. For example, if a teacher observes that some students do not grasp a concept, he can design a review activity or use a different instructional strategy. Likewise, students can monitor their progress with periodic quizzes and performance tasks. The results of FA are used to modify and validate instruction.

Thus, formative assessment is part of the instructional process. It informs both teachers and students about student understanding at a point when timely adjustments can be made. These adjustments help to ensure students achieve targeted standards-based learning goals within a set time frame. Although FA strategies appear in a variety of formats, there are some distinct ways to distinguish them from summative assessments.

One distinction is to think of FA as "practice". Formative assessment helps teachers determine next steps during the learning process as the instruction approaches the summative assessment of student learning. Swearingen draws a good analogy for this - the road test for getting a driver's license. What if, before getting your driver's license, you received a grade every time you sat behind the wheel to practice driving? What if your final grade for the driving test was the average of all of the grades you received while practicing? Because of the initial low grades you received during the process of learning to drive, your final grade would not accurately reflect your ability to drive a car. Your final driving test, or summative assessment, would be the accountability measure that establishes whether or not you have the driving skills necessary for a driver's license not a reflection of all the driving practice that leads to it (Swearingen 2002). The same is true for classroom instruction, learning, and assessment.

Another distinction is student involvement. If students are not involved in the assessment process, formative assessment is not practiced or implemented to its full effectiveness. Students need to be involved both as assessors of their own learning and as resources to other students. There are numerous strategies teachers can implement to engage students. In fact, research shows that the involvement in work increases students' motivation to learn. This does not mean the absence of teacher involvement. On the contrary, teachers are important in identifying learning goals, setting clear criteria for success, and designing assessment tasks that provide evidence of student learning.

A significant component of engaging students in the assessment of their own learning is providing them with descriptive feedback as they learn. In fact, research proves descriptive feedback to be the most significant instructional strategy to move students forward in their learning. It provides students with an understanding of what they are doing well, links to classroom learning, and gives specific input on how to reach the next step in the learning progression.

The following formative assessments are observed in Armenian schools and universities: quizzes and essays, diagnostic tests, lab reports, etc. Yet, computer-aided formative assessment is not common in Armenian educational system. It should be applied more widely to make the assessing process more productive.

Summative Assessments (SA) are given periodically to determine at a particular 
point in time what students know and do not know. P. Black explaining SA through analogy, stated, "When the cook tastes the soup, that's formative assessment; when the customer tastes the soup, that's summative assessment" (Black 2003). Thus, as we have mentioned above, formative assessment focuses on the process of assessing and using feedback, whereas summative assessment tends to focus on the product. Concisely, summative assessment is a test, the purpose of which is evaluative. It is used to evaluate the effectiveness of instructional programs and services at the end of an academic year or at a pre-determined time. The goal of SA is to make a judgment of student competency after an instructional phase is complete. Examples of SA which are applied in Armenian schools and universities are: end-of-unit or chapter tests, mid-term tests, end-of-term or semester exams. Computer-aided summative assessment in Armenian educational system is becoming more common, especially within Republic Olympiad Tests and Entrance Exams.

In order to maximize the efficiency of summative and formative assessment, the following factors must be considered: variety, volume, validity, and reliability.

As for the first factor, traditionally true/false and selected-response test items have been popular methods of assessing students. They are limited in scope and typically test each student's capacity for rote memorization. However, assessment should include all three domains of learning; cognitive, affective, and psychomotor. In addition, assessments of the cognitive domain should reflect its higher levels, such as synthesis and evaluation. So, instructors should use a variety of assessment techniques, such as portfolios, cooperative research projects, and performance tests.

The quantity of assessment which contributes to the final result should be the minimum amount necessary to ensure a valid result. The trouble is that teachers often require more summative assessments than necessary.

The validity of assessment refers to the degree to which the assessment measures performance on the aspects of the course which are important. For example, if you want to measure a student's ability of unknown text comprehension, you are not supposed to give him a test on grammar.

The factor of reliability is well illustrated through the following analogy made by Kellough. Suppose that one wishes to determine how fast one's car is traveling; a valid assessment tool is the speedometer. However, if one's car travels at $60 \mathrm{mph}$ the speedometer registers $50 \mathrm{mph}$, the speedometer is not reliable. Similarly, a test can be valid, but not reliable (Kellough 1999). However, instructors can facilitate reliability. For instance, one method for ensuring reliability when grading a research paper is using a rubric and allowing the students to have copies of it. If the rubric is well designed, several instructors could score the same paper using the rubric and arrive at similar scores. Thus, the hallmark of assessment reliability is the reproducibility of assessment results.

To sum up, assessment should be more than merely a test at the end of instruction to see how students perform under special conditions; it should be a central part of instruction that informs and guides teachers as they make instructional decisions. Assessment should not merely be done to students; it should also be done for students, to guide and improve their learning. 


\section{References:}

1. Black, P.; Harrison, C.; Lee, C.; Marshall, B. \& Wiliam, D. (2003) Assessment for Learning: Putting it into Practice. Berkshire, England: Open University Press.

2. Brookhart, S.M. (1999) Educative Assessment: Designing Assessments to Inform and Improve Student Performance. San Francisco: Jossey-Bass.

3. Brown, S. and Glasner, A. (Eds) (1999) Assessment Matters in Higher Education: Choosing and Using Diverse Approaches, Buckingham: Open University Press.

4. Davies, P.; Hodkinson, S. and Reynolds, P. (Eds) (2000) Innovative Approaches to Learning and Teaching in Economics and Business Higher Education. Staffordshire University Press, Stoke on Trent.

5. Kellough, R.D. and Kellough, N.G. (1999) Secondary School Teaching: A Guide to Methods and Resources; Planning For Competence. New Jersey: Prentice Hill, Upper Saddle River.

6. Swearingen, R. (2002) A Primer: Diagnostic, Formative, and Summative Assessment. Washington: Heritage University Press.

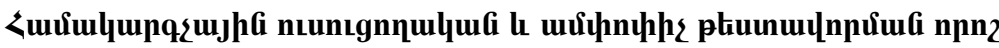 hpưfiuhungtiph 2nıp2}

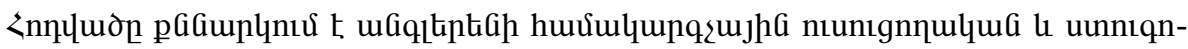

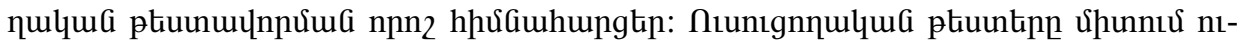

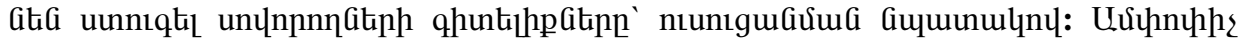

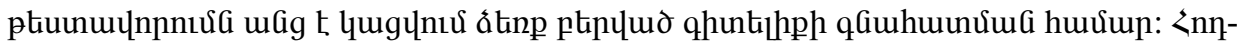

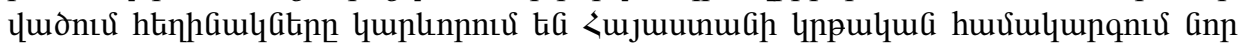

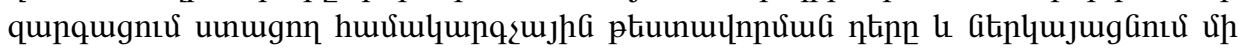

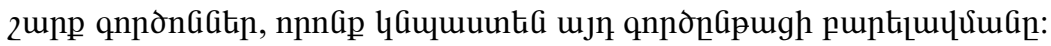

